\title{
PRESENCIA DE LA MARCA DE CIUDAD EN PÁGINAS WEB INSTITUCIONALES Y REDES SOCIALES DE CIUDADES ECUATORIANAS, COMO FACTOR DE DIFERENCIACIÓN
}

\section{PRESENCE OF THE CITY BRAND ON INSTITUTIONAL WEBSITES AND SOCIAL NETWORKS OF ECUADORIAN CITIES, AS A DIFFERENTIATION FACTOR}

\author{
José Pancorbo Sandoval, Ph.D. \\ http://orcid.org/0000-0002-8082-6720 \\ Universidad Tecnológica Equinoccial, Sede Santo Domingo, Ecuador. \\ pancor49@gmail.com \\ Sonia Leyva Ricardo, Mgtr. \\ http://orcid.org/0000-0002-4556-2301 \\ Universidad Tecnológica Equinoccial, Sede Santo Domingo, Ecuador. \\ sonia.leyva@ute.edu.ec \\ Andy López Gómez, Lic. \\ http://orcid.org/0000-0002-0617-0823 \\ Grupo de Estudios en Planificación y Desarrollo Inteligente del Territorio, \\ Santo Domingo, Ecuador. \\ andylg_10@hotmail.com \\ Ana Torres Estupiñán, Lic. \\ http://orcid.org/0000-0002-1717-829X \\ Investigadora independiente, Santo Domingo, Ecuador. \\ anapatriciaapte@gmail.com
}

\section{ARTÍCULO DE REFLEXIÓN}

Recibido: 10 de octubre de 2021

Aceptado: 19 de noviembre de 2021

\section{RESUMEN}

Las urbes ecuatorianas tienen la posibilidad de desarrollarse a partir de sus potencialidades, identificando atributos que les permitan atraer inversiones, generar empleo y establecer una posición competitiva. Para esto, es necesario definir, las acciones y los atributos de notoriedad que las hagan reconocer como ciudad de oportunidades, para lo cual se desarrollan estrategias de marketing, que, posibiliten bajo el paraguas de una marca atractiva diferenciarlas en el mercado urbano actual. Es por ello que el objetivo del presente estudio es poder identificar cuáles son los principales atributos más comunes que utilizan los decisores para posicionar en el mercado nacional e internacional en ciudades ecuatorianas seleccionadas para el estudio. La metodología que abordó la investigación responde a un paradigma cualitativo de tipo revisión documental y del análisis de la presencia de las marcas de ciudades en las páginas web institucionales y redes sociales de ciudades seleccionadas 
para la presente investigación. Los resultados derivados permiten validar que un alto porcentaje de marcas de ciudades se centran en el sector turístico, sin que exista un proyecto con una visión holística sobre el papel de la marca en el desarrollo de las ciudades.

Palabras claves: atributos de notoriedad, marketing, marca ciudad, competitividad urbana

\section{ABSTRACT}

Ecuadorian cities have the possibility of developing from their potential, identifying attributes that allow them to attract investment, generate employment and establish a competitive position. For this, it is necessary to define the actions and attributes of notoriety that make them recognized as a city of opportunities, for which marketing strategies are developed, which, under the umbrella of an attractive brand, make it possible to differentiate them in the current urban market. That is why the objective of this study is to be able to identify which are the main most common attributes used by decision-makers to position themselves in the national and international market in Ecuadorian cities selected for the study. The methodology covered by the research responds to a qualitative paradigm of a documentary review type and the analysis of the presence of city brands on the institutional web pages and social networks of the cities selected for this research. The derived results allow to validate that a high percentage of city brands are focused on the tourism sector, without there being a project with a holistic vision on the role of the brand in the development of cities.

Keywords: attributes of notoriety, marketing, city brand, urban competitiveness

\section{INTRODUCCIÓN}

Desde la década del 90 del siglo XX, se inicia a considerarse la marca de ciudad como una disciplina académica transdisciplinaria, que se considera por algunos investigadores como parte del subsistema marketing que se conoce como "marketing de lugares o ciudades" o "venta de lugares" y/o como "promoción de lugares". Los tres conceptos analizan la necesidad que tienen los territorios de posicionarse para competir en los mercados globales desde una perspectiva eminentemente económica y que coinciden en considerar como ejes de posicionamiento, los valores tangibles e intangibles de una región específica y, por tanto, su identidad.

El branding integra la infraestructura, el entorno natural, la idiosincrasia de la población y la cultura, pero, sobre todo, se relaciona con lo que la población hace, siente y espera (Gómez y Salinas 2017). Por eso la gestión de la marca de una localidad requiere la suma de varios pensamientos, disciplinas y conocimientos. 
Esta valoración previa permite a los autores del presente estudio, identificar básicamente tres perspectivas en que se desarrollan los estudios de marca ciudad y que se pueden resumir en los siguientes: la marca como parte del producto urbano, como elemento originado de la cultura e historia de la región y como estrategia política y de gobernanza, esta última marcada por una marcada intención de influir en la percepción pública de las personas, lugares, organizaciones, proyectos y objetos físicos.

Lamentablemente la mayoría de los actores locales confunden a la marca ciudad como la imagen deseada que se desea tener sobre la misma, sin considerar los valores intrínsecos de la misma, es por ello que el concepto de la marca de lugar está, por tanto, totalmente ligada al orden político.

Por lo tanto, las administraciones públicas se convierten en actores clave en el desarrollo de campañas de marca de lugar, no solo en el contexto local sino también a nivel nacional e internacional, con el claro objetivo de posicionar a la ciudad en el mercado global para atraer inversores y recursos a sus planes de desarrollo territorial.

Las ciudades ecuatorianas no están encentras de este propósito político y económico de atraer recursos humanos y económicos a sus proyectos urbanos, tal y como lo muestran estudios precedentes como el de Alvarado Moreno (2015), Zambrano Mendoza (2015) y más recientemente Paredes Zevallos (2020), Es por ello que los autores del presente proyecto de investigación, proponen realizar una revisión sobre la utilización de la marca ciudad en urbes ecuatorianas.

Considerando la ausencia de estudios estadísticos sobre el impacto de la marca ciudad en el desarrollo estratégico de las ciudades, los autores del presente proyecto han desarrollado un estudio exploratorio sobre la utilización de las redes sociales como instrumento de comunicación de los valores de la ciudad como destino de productos y servicios urbanos.

El presente estudio pretende mostrar la existencia de sinergias entre cuatro conceptos básicos, que son: la marca de lugar, su objetivo de contribuir a la planificación sostenible, su influencia en las decisiones de gobernanza pública y, finalmente, su capacidad de ser central en la definición de programas de diplomacia pública fuera de lo habitual dominio centrado en el estado.

Considerando estudios precedentes como los de Pancorbo et al (2017) y Vélez Bermello (2019), se seleccionan a las ciudades de Quito, Guayaquil, Cuenca, Manta y Santo Domingo, considerando, la variable de presencia en redes sociales y en los medios de comunicación del país e internacionalmente, específicamente en el sector turístico, ya que es donde se encuentra la mayor cantidad de citas sobre estas ciudades. 


\section{REVISIÓN DE TEÓRICA}

La revisión teórica previamente realizada en el presente estudio, ha permitido visualizar diferentes enfoques para abordar el concepto de marca ciudad, entre las cuales se encuentra su valoración desde la planificación estratégica, desde el marketing, desde la sociología y por supuestos desde el enfoque urbano; este último se ha utilizado en estudios del ámbito de la gobernanza y las políticas públicas.

Como se ha mencionado anteriormente, las urbes de Quito, Guayaquil, Cuenca, Manta y Santo Domingo, han identificado oportunidades atractivas de mercados e inversión, que les permite ser competitivo y crear las condiciones para ello, incrementando su potencial socioeconómico, incidiendo paralelamente en el aumento de la calidad de vida de sus residentes, creando oportunidades a los empresarios e inversores, haciéndose atractivas a los visitantes, identificándose a posibles competidores, tomando como base los recursos locales, en sinergia creativa con lo global.

Desde la década del 90 del pasado siglo, se inicia el empleo del concepto de marketing de ciudad, que ha sido el empleado en los últimos años en la gestión de las ciudades más emprendedoras a escala internacional como son los casos de Glasgow (Escocia), Bilbao (España), Rosario (Argentina), entre otras, que son casos exitosos en la búsqueda de nuevas visiones, misiones y objetivos, pasando a una nueva forma de planificación y gestión de ciudad que se basa en la creación de valor y en una nueva forma de interactuar con sus públicos objetivo, pues se trata precisamente de un cambio en la forma de pensar la ciudad.

En 1999, Pancorbo (1999) presenta un sistema de indicadores urbanos para evaluar el desarrollo estratégico de 55 ciudades españolas desde la visión del marketing de ciudad, siendo uno de los primeros análisis del marketing de ciudad en Hispanoamérica, iniciándose así el desarrollo de una escuela hispanoamericana, que se diferencia de la escuela francesa (Noissette y Vallerugo, 1996) y de Kotler,v; Asplund, ; Rein, y Haider, 1999).

De tal modo, los autores del presente estudio identifican dos claras tendencias en la aplicación del marketing de ciudad: la escuela francesa, liderada por Noissette y Vallerugo (1994) y la escuela norteamericana presidida por Kotler et all (1999) y que en su esencia se desmarcan por diferentes visiones, ya que la escuela norteamericana defiende la asociación público -privada, mientras que la escuela francesa se desmarca por el protagonismo del gobierno y por ende del sector público. 
No obstante, ambas escuelas coinciden en que es vital para el marketing y en el ámbito de la gestión de ciudades, centrar la atención en determinados atributos y características de las ciudades, para aumentar no solo sus atractivos, sino los beneficios de experimentar la ciudad, lo que alcanza un grado mayor de importancia en el escenario actual del Covid-19.

Al respecto, Elizagarate (2008), señala que implica un cambio de orientación y una manera filosófica de gestión al considerar que la ciudad se encuentra inmersa en un proceso de intercambio, que da lugar a transacciones entre los servicios y las atracciones de la ciudad y los ciudadanos, inversores, empresas o turistas, que crea además una red de relaciones, y en donde lo fundamental es conseguir la satisfacción de los públicos de la ciudad.

Indudablemente la identidad y la imagen urbana han acompañado desde sus inicios al marketing de ciudad, siendo ambas variables importantes, ya que por una parte la identidad urbana caracteriza e identifica a una ciudad, mientras que la imagen urbana, van a aportar los atributos esenciales de la misma, guiándola en su desarrollo estratégico.

Autores como Zenker, Braun y Petersen, (2017) señalan que la marca de los lugares considera a las variables imagen e identidad como esenciales en la elaboración de la misma, aunque en muchas ocasiones queda reducido a en mensajes simplificados, por lo que la efectividad de tales estrategias para las marcas complejas sigue siendo cuestionables por dichos autores.

Otros expertos como como Gertner (2011), Braun, (2012); Hanna et al (2015), Kotler y Kotler; (2016) indican que los residentes, en particular, poseen un conocimiento parcial de su ciudad en cuanto a historia y hechos que son importantes para poder estructurar adecuadamente a la marca y no desvirtuar la esencia de la ciudad en sí. En este sentido es interesante la utilización de la co-creación de la marca para generar una marca que responda a las expectativas de los residentes y el resto de demandantes del producto ciudad tal y como apunta Sarasvuo, Rindell y Kovalchuk, (2022), cuando indican que la co-creación en branding posibilita generar un proceso de interacción intencional entre dos o más partes que influye en una marca.

Si bien la marca de lugar a menudo toma la forma de marca de destino para atraer turistas (Park \& Petrick, 2006; Jacobsen (2009), la marca de destino en los últimos años ha iniciado a considerar otros grupos de interés como son los residentes e inversores potenciales y actuales (Hanna y Rowley, 2015; Palmer, Koenig-Lewis y Jones, 2013).

Coinciden los autores de esta investigación de que la marca de lugar podría entenderse como el árbol genealógico tal y como apuntan Zenker y Braun (2010), donde es vital considerar la percepción y la co-creatividad de la marca ciudad, considerando a los residentes, como acertadamente apunta Freire (2009). 
Desde la perspectiva de la marca ciudad, a través de la búsqueda de recursos relevantes, se pueden identificar los factores más importantes que inciden en la marca del espacio urbano, autores como Magnoni et al (2021) señalan que la comunicación y gestión de la imagen de marca de la ciudad debe considerar las raíces culturales de la región, incluyendo su historia y factores socioculturales como pueden ser sector económico y características culturales de la población residente. No obstante, se debe considerar oportuna la opinión de que la noción de territorio debe ir más allá de la idea reduccionista y estática de un mero espacio físico dado, proveedor de recursos naturales y materiales, para ser concebido como un proceso de construcción social determinado por los actores locales y sus interacciones para valorizar los recursos territoriales (Reina-Usuga, Parra-López, Haro-Giménez, 2022).

\section{Utilización de la marca ciudad en urbes ecuatorianas.}

Padilla A.C. \& Piedra M.E. (2015), estudiaron la conexión entre la marca ciudad para la ciudad de Cuenca y la percepción de su imagen en los ciudadanos, concluyendo de que la marca ha sido generada por los alcaldes de turno desde 1994, careciendo de estudios técnicos bien fundamentados. La mayoría de las marcas así elaboradas coincidieron en tener en cuenta variables como s son la variable Comercio, Industria, Cultura, Arquitectura, Gente, Religión, Tradición y Turismo para poder determinar la importancia que es tener una marca ciudad propia y saber el punto de vista que tiene la gente de su ciudad.

Uno de los primeros estudios referidos a la marca ciudad, lo propone en el 2015 el experto Galiano, cuando analiza críticamente el caso de la ciudad de San Miguel de lbarra, mediante una investigación y análisis de factores influyentes en la construcción y promoción de una marca ciudad patrimonial, concluyendo lo inadecuado la estrategia de comunicación al ser de baja calidad por su contenido y sus imágenes presentadas.

Según un artículo publicado por Godoy M.E. \& Godoy D. (2017) en la Revista Turydes con el tema "Diseño de una propuesta de marca territorial para la ciudad de Loja como estrategia turística", los autores defienden su criterio de que la creación de marca territorial debe considerar los factores turístico y cultural como variables fundamentales. En esta investigación para determinar la marca territorial tomaron en cuenta lo propuesto por Anholt (2018): Presencia (conocimiento de la ciudad, el territorio y su clima), el Potencial de la ciudad (las oportunidades económicas, referidas al aspecto turístico, industria y educacionales), y como tercer criterio, la Gente (características de sus habitantes).

Según la opinión de Guamán (2016) en su tesis "Diseño de un Cuadro de Mando Integral como elemento estratégico para la marca Salcedo", en su mayoría los visitantes conocen poco sobre la ciudad, lo que demuestra un escaso nivel de promoción de esta, por parte de los estrategas del gobierno, ya que, según el estudio ya mencionado, los visitantes en si lo 
que conocen del lugar son trasmitidos por amigos y familiares que son residentes de Salcedo. El análisis realizado en este estudio indica que existen pocas diferencias entre la valoración que hacen los visitantes de la ciudad de Salcedo y la que hace los residentes, encuestados, por ende, se deriva que ambos segmentos coinciden en sus apreciaciones.

En este mismo estudio identifica a la variable "Economía" como la más mencionada por las investigaciones para evaluar la marca ciudad, seguidas de industria, comercio, calidad de vida, ambiente, gente y turismo (Guamán, 2016).

En un estudio aplicado a la ciudad de Montañita (Romero Baque y Narváez, 2016) se parte de la visión de la comuna desde el lado emocional, su antepasado, sitios emblemáticos y turísticos de la ciudad, pero coincide con otros estudios en lo referente de lograr ventajas competitivas solo centrándose en el factor turismo.

Contrastando con estos resultados es interesante que otras variables como son arquitectura, cultura, Imagen, Institucional, manejo del destino, religión, tradición, servicios y presencia, son menos mencionados a la construcción de la marca ciudad.

Crudele (2018), en su trabajo titulado "Estudio de la marca Ciudad Loja como atractivo de turismo nacional y extranjero en el Ecuador", insiste en que la utilización de la marca ciudad debe ser una importante estrategia para el posicionamiento de la ciudad, como sería en este caso de Loja, sin considerar otras áreas de potencial interés para ser asociadas al concepto de marca ciudad.

Los expertos en desarrollo territorial Godoy Zúñiga y Vásquez (2018), confunden en su estudio al marketing urbano y al branding como variables diferenciadas, cuando en la realidad el branding es un elemento dentro del sistema de marketing de ciudad. De igual modo se centra en el tema del turismo como principales ítems a considerar en la aplicación de técnicas de marketing de ciudad.

Los autores Corral y Pineda (2017) aseveran que la utilización de técnicas de branding contribuyeron al reconocimiento de la marca ciudad "Atuntaqui", además de que ayudo en la búsqueda de diferenciación de la competencia en su momento.

En el 2020, los expertos Poveda Benites y Gómez Behr, hacen un interesante análisis sobre la campaña Ecuador Ama la Vida y como a su juicio, no logra su objetivo a largo plazo, ya que no considero el componente humano como un factor estratégico en su plan de comunicación, ya que se centran en las variables turísticas.

Otra arista interesante sobre la marca país, la brinda el investigador Espinosa (2020) al señalar la importancia de que la Marca Ecuador sea una política de Estado y no de gobierno. Los autores del presente artículo científico coinciden con este criterio ya que la marca país 
debe incluir los valores más importantes de una ciudad y por ende debe considerar la idiosincrasia de los ciudadanos, la historia y valores históricos y sociales y no meramente enfocarse en valores turísticos o los intereses políticos del gobernante de turno.

En este mismo sentido autores como Ponce-Andrade et al (2020) señalan que, en la promoción de la ciudad de Manta, se emplea de forma muy sesgada los atributos de la ciudad en las redes oficiales y sociales, e inclusive se utiliza como una herramienta para posicionar el poder de determinadas decisiones administrativos.

Al revisar otros estudios como el de Castro Analuiza y Sánchez Villalba (2020) se corrobora la valoración de los autores del presente estudio, de que el leitmotiv de la utilización de la marca ciudad es con el objetivo de promocionar turísticamente una urbe, desechando otros atributos quizás más estratégicos como es el sector empresarial, cultural y económico.

El interesante estudio de Paredes Cevallo (2020) demuestra a través de la aplicación del modelo PRGS (P-Presencia, R-Respuesta, G-Generación, S-Sugerencia) para estudiar las redes sociales; y la realización de un focus group para generar estrategias de branding, de que la ciudad de Quito no logra aun tener una marca ciudad definida.

Otras variables que se han considerado por investigadores ecuatorianos para el desarrollo del modelo de marca-ciudad son la arquitectura, clima, reservas ecológicas y la manera en que se da a conocer la ciudad (Tobar y Moreno, 2020).

Sin embargo, en este último estudio sobre la ciudad de Latacunga, se evidencia nuevamente el error (a juicio de los autores del presente estudio), de que no se considera como importante valor agregado la infraestructura de servicios y empresariales con que cuenta la ciudad en la construcción de la marca ciudad.

Luego de analizar los resultados de los estudios precedentes se hace evidente la desacertada estrategia de centrar a I marca en el sector turístico y político, obviándose otras variables como son los siguientes: servicios, Emprendimiento, Manejo del Turismo, Cultura, Seguridad, Ambiente, Gobierno (Institucional), Innovación y Salud.

\section{MATERIALES Y MÉTODOS}

Se aplicará el denominado análisis de contenidos, ya que es una herramienta basada en el análisis y la interpretación de fuentes documentales lo cual posibilita identificar códigos utilizados por el emisor de los documentos analizados.

En ésta investigación se trabajará con el tipo de metodología mixta, es decir cuantitativa y cualitativa; con la primera se obtiene resultados medibles, utilizando técnicas que generan datos los cuales se recolectan y analizan para la toma de decisiones. 
Con la segunda, de la misma forma, se usa técnicas que buscan comprender al fenómeno de estudio en su ambiente usual, cuyo resultado puede servir de complemento en el conocimiento del mercado.

En cuanto al nivel de la investigación será descriptivo, ya que ayuda a detallar la utilización de la marca ciudad en páginas gubernamentales y redes sociales (análisis interno y externo) para generar las estrategias más apropiadas. Y finalmente la modalidad de la investigación de la investigación documental, ya que se recopila y selecciona información a través de la lectura de documentos, libros, revistas, grabaciones, filmaciones, periódicos, bibliografías, etc., relacionados con el presente estudio.

Las técnicas de investigación que se utilizaron son:

Bibliográfica: Toda aquella información documental que obtuvo de estudios precedentes sobre marca ciudad internacional y nacionales Como se ha mencionado anteriormente se empleará la Investigación documental, al ser una variante de la investigación científica, cuyo objetivo fundamental es el examinar de diferentes fenómenos (de orden histórico, psicológico, sociológico, etc.), utilizando a técnicas muy precisas, de la documentación existente, que directa o indirectamente, aporte la información

El método descriptivo en el presente trabajo juega un papel fundamental en el desarrollo de toda aquella información general obtenida en el método anterior, permitiendo conocer acerca de las menciones a temas sobre la ciudad en internet.

Mediante este método se pueden obtener resultados claros de la elaboración y contenido de asociado a lo que se menciona sobre las ciudades seleccionadas en el estudio que son Cuenca, Guayaquil, Quito Manta y Santo Domingo.

Como una primera etapa se realizó una revisión bibliográfica sobre estudios de expertos ecuatorianos desde el 2015 hasta el 2020, con el objetivo de identificar los principales atributos y estrategias que se proponen para el desarrollo de la marca ciudad a través de un muestreo por conveniencia.

En una segunda etapa se realiza una revisión de las redes sociales sobre la presentación de la marca ciudad por gobiernos locales y actores locales. Considerando de que según datos del informe Ecuador Estado Digital 2021; Facebook, Instagram, TikTok y Twitter son las más populares en Ecuador, siendo Facebook la red social más visitada en navegadores web y de que, un ecuatoriano pasa en promedio 18,50 minutos por día en Facebook y que revisa 8,83 páginas por visita, los autores del presente estudio seleccionan a la misma como principal objeto de estudio. 
A continuación, en la tabla siguiente se indican las cuentas de Facebook, y otros sitios web de las ciudades de Quito, Guayaquil, Manta, Santo Domingo de los Colorados que se utilizaron para la recolección de la información de la investigación.

Tabla 1

Registro de las cuentas de Facebook, y otros sitios web.

\begin{tabular}{|c|c|c|}
\hline CIUDAD & FACEBOOK & LINK DE EVENTOS \\
\hline Quito & $\begin{array}{c}\text { https://www. } \\
\text { facebook.com/ } \\
\text { MunicipioQuito/ }\end{array}$ & $\begin{array}{l}\text { http://www.quitoinforma.gob.ec/2018/11/15/plataforma-digital- } \\
\text { turistica-de-quito-entre-los-seis-mejores-proyectos/ } \\
\text { http://www.quitoinforma.gob.ec/2018/11/12/quito-promociona- } \\
\text { su-oferta-turistica-en-londres/ } \\
\text { http://www.quitoinforma.gob.ec/2019/01/29/quito-consolida- } \\
\text { alianzas-estrategicas-en-turismo-en-fitur-2019/ } \\
\text { https://www.quito-turismo.gob.ec/modelos-de-negocios- } \\
\text { sostenibles-para-proyectos-turisticos-adaptados-a-tiempos-de- } \\
\text { covid-19/ } \\
\text { https://www.quito-turismo.gob.ec/repensando-un-macro-entorno- } \\
\text { para-el-desarrollo-del-turismo-post-covid-19/ } \\
\text { https://www.quito-turismo.gob.ec/normativa-tecnica-de-turismo- } \\
\text { de-aventura-canopy/ } \\
\text { https://www.quito-turismo.gob.ec/turismo-mice-analisis-y- } \\
\text { proyecciones/ } \\
\text { https://www.quito-turismo.gob.ec/el-rol-de-los-hoteles-en-la- } \\
\text { cadena-de-valor-del-turismo-mice/ } \\
\text { https://www.quito-turismo.gob.ec/los-eventos-deportivos-en-la- } \\
\text { oferta-del-turismo-mice/ } \\
\text { https://www.quito-turismo.gob.ec/implementacion-de-protocolos- } \\
\text { de-bioseguridad-para-establecimientos-de-alojamiento-zonas- } \\
\text { rurales-haciendas-turisticas-hosterias-lodges-campamento- } \\
\text { turistico/ } \\
\text { https://www.quito-turismo.gob.ec/implementacion-de-protocolos- } \\
\text { de-bioseguridad-para-transporte-turistico/ } \\
\text { https://www.quito-turismo.gob.ec/turismo-creativo/ } \\
\text { https://www.quito-turismo.gob.ec/turismo-cultural/ } \\
\text { https://www.quito-turismo.gob.ec/turismo-gastronomico-cocina- } \\
\text { ecuatoriana-de-innovacion/ } \\
\text { https:/www.quito-turismo.gob.ec/turismo-religioso/ }\end{array}$ \\
\hline
\end{tabular}




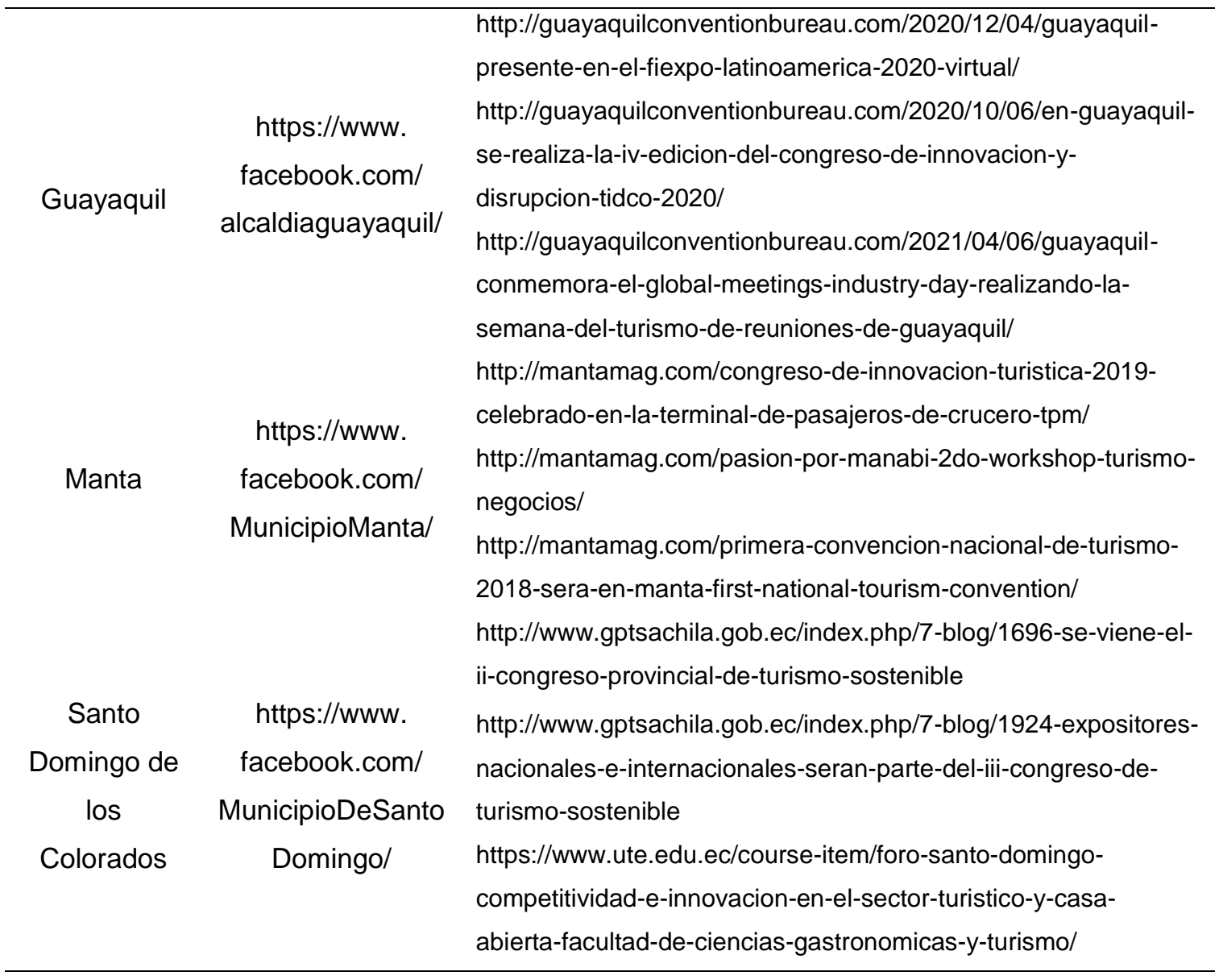

Fuente: Elaboración propia.

La tabla a continuación da a conocer los sitios web de los eventos que se realizaron sobre el tema de reactivación y turismos.

Tabla 2

Sitios web de los eventos que se realizaron reactivación turística.

\begin{tabular}{cc}
\hline EVENTOS QUE SE REALIZARON SOBRE EL TEMA DE REACTIVACIÓN, TURISMOS \\
\hline \\
https://www.ute.edu.ec/course-item/modelo-de-gestion-turistica-en-galapagos/ \\
https://www.ute.edu.ec/course-item/conversatorio-reactivacion-del-turismo-en-ecuador/ \\
https://www.ute.edu.ec/course-item/curso-turismo-accesible/ \\
https://www.ute.edu.ec/course-item/turismo-master-class/ \\
\\
https://www.ute.edu.ec/course-item/conferencia-proyecto-carbon-neutro-y-turismo/ \\
https://www.ute.edu.ec/course-item/conferencia-proyecto-carbon-neutro-y-turismo/ \\
CAPACITACIONES 40 horas - https://www.turismo.gob.ec/capacitacion/ \\
CAPACITACIONES 40 horas - https://www.turismo.gob.ec/capacitacion/ \\
CAPACITACIONES 40 horas - https://www.turismo.gob.ec/capacitacion/ \\
CAPACITACIONES 40 horas - https://www.turismo.gob.ec/capacitacion/ \\
CAPACITACIONES 40 horas - https://www.turismo.gob.ec/capacitacion/ \\
Capacitaciones
\end{tabular}


https://www.turismo.gob.ec/turismo-en-tiempo-de-pandemia-webinar-para-concienciarsobre-las-medidas-de-bioseguridad/

https://www.ute.edu.ec/course-item/webinarute-turismo-y-resiliencia-certificaciones-desostenibilidad-como-instrumento-de-reactivacion-de-empresas-turisticas-2/

https://www.ute.edu.ec/course-item/webinarute-reactivacion-del-turismo-accesible-postpandemia/

https://www.ute.edu.ec/course-item/webinarute-derecho-a-la-ciudad-y-planificacionturistica/

https://www.facebook.com/MinisterioTurismoEcuador/photos/viernes-1500-participa-enla-webinar-campa\%C3\%B1a-de-promoci\%C3\%B3n-tur\%C3\%ADstica-en-tiempos-

Webinar $\mathrm{d} / 3233057750061256$

https://www.facebook.com/MinisterioTurismoEcuador/photos/viernes-1500-participa-enla-webinar-campa\%C3\%B1a-de-promoci\%C3\%B3n-tur\%C3\%ADstica-en-tiempos$\mathrm{d} / 3232509290116102$

https://www.facebook.com/MinisterioTurismoEcuador/photos/viernes-1500-participa-enla-webinar-campa\%C3\%B1a-de-promoci\%C3\%B3n-tur\%C3\%ADstica-en-tiempos$\mathrm{d} / 3215211851845846$

facebook.com/MinisterioTurismoEcuador/photos/viernes-1500-participa-en-la-webinarcampaña-de-promoción-turística-en-tiempos-d/3214121635288201

https://www.facebook.com/MinisterioTurismoEcuador/photos/viernes-1500-participa-enla-webinar-campa\%C3\%B1a-de-promoci\%C3\%B3n-tur\%C3\%ADstica-en-tiempos$\mathrm{d} / 3208034885896876$

https://www.turismo.gob.ec/en-congreso-se-analizan-las-realidades-y-desafios-del-

Congreso turismo-en-ecuador/ http://redisd.org/index.php/es/congresos/2do-congreso-sd-investiga-ii-cisdi2019/item/50-at4-ciencias-administrativas-y-desarrollo-local https://www.facebook.com/MinisterioTurismoEcuador/posts/3208034945896870/ https://www.ute.edu.ec/course-item/amadeus-retos-y-perspectivas-en-el-sectorturistico-en-ecuador-y-america-latina/ https://dialnet.unirioja.es/servlet/articulo?codigo=6353752

Otros https://repositorio.pucesa.edu.ec/bitstream/123456789/1767/1/76272.pdf http://biblioteca.uteg.edu.ec:8080/bitstream/handle/123456789/155/ANALISIS-DEMARCA-CIUDAD-GUAYAQUIL-Y-PROPUESTA-DE-NUEVOS-VALORES-YCOMPONENTESpdf.pdf?sequence $=1$ \&isAllowed $=\mathrm{y}$ http://dspace.uazuay.edu.ec/bitstream/datos/4046/1/10645.pdf

Fuente: Elaboración propia. 
Los pasos del procedimiento aplicado se exponen a continuación:

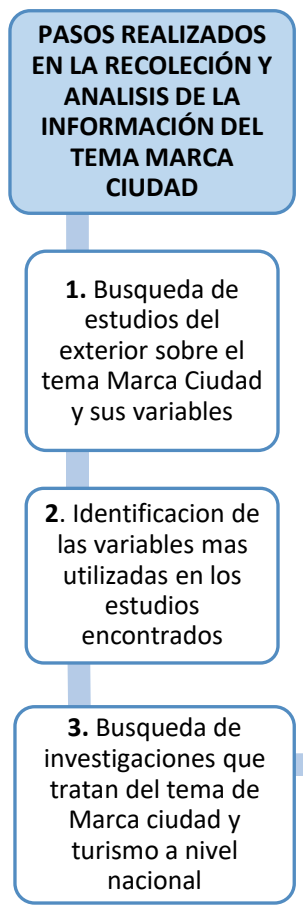

Figura 1. Pasos

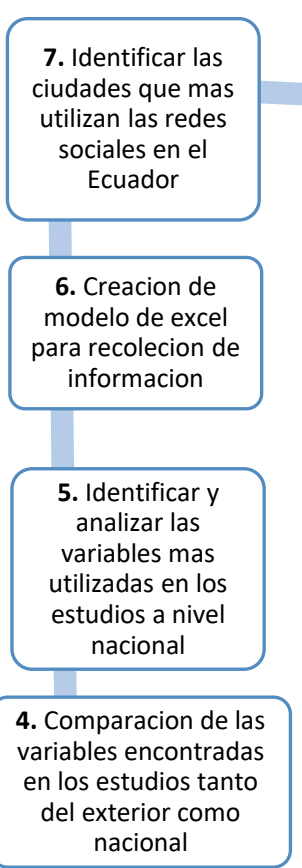

8. Selección de las 5 ciudades que mas utilizan las redes sociales (Quito, Guayaquil, Cuenca, Santo Domingo y Manta)
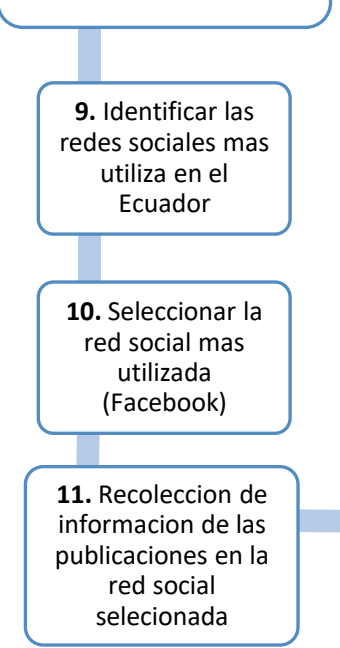

13. Analisis de la informacion recogida

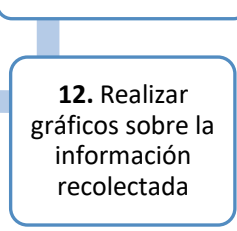

Fuente: Elaboración propia.

En una tercera etapa se realizó un análisis a través de dos técnicas, una primera mediante el motor de búsqueda Google con el objetivo de localizar eventos asociados a la marca ciudad en redes ecuatorianas y un segundo análisis a través del uso de la herramienta de Google Trends, que es una herramienta que, en base a los datos registrados en el motor de búsqueda de Google, muestra de manera dinámica y gráfica la frecuencia de temas y términos de búsqueda de los usuarios en determinado lapso de tiempo o región del mundo. Gráficamente el procedimiento empleado quedaría del modo siguiente:

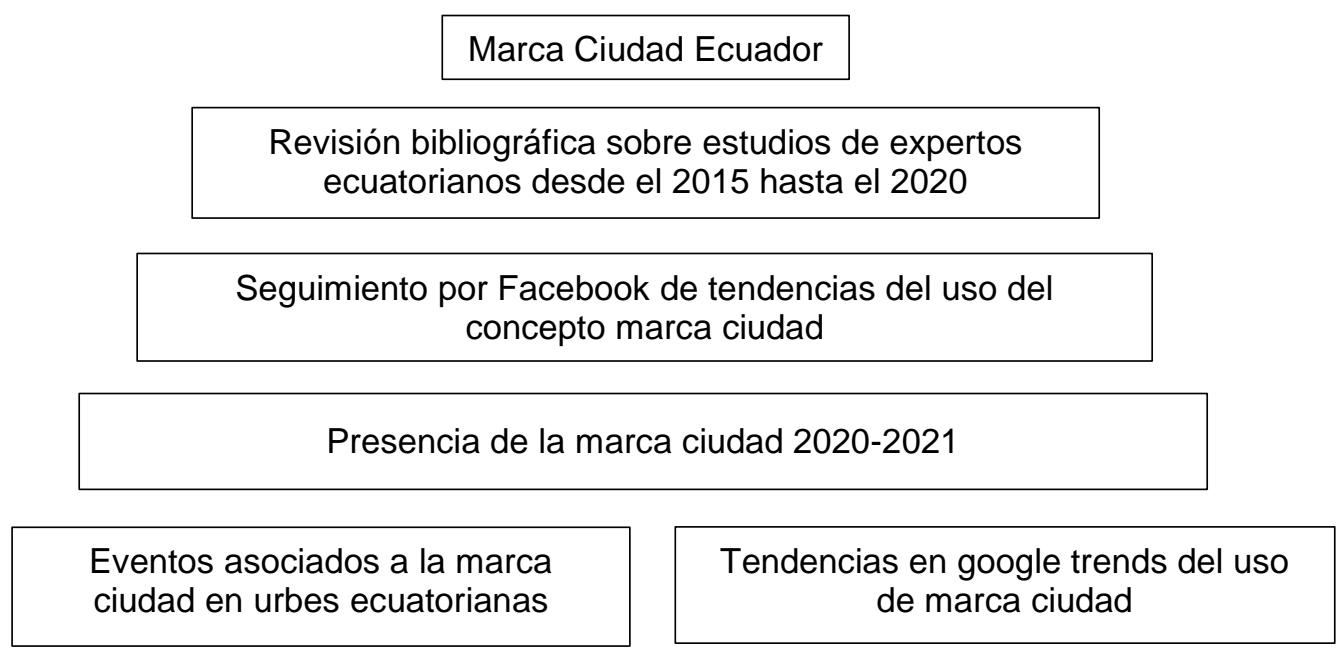

Figura 2. Frecuencia de temas y términos de búsqueda de los usuarios. Fuente: Elaboración propia. 


\section{RESULTADOS}

A partir de la revisión de estudios de expertos sobre estrategias y tendencias de la marca ciudad en el caso de ciudades del país, los autores realizan el siguiente análisis.

Una vez revisado 20 artículos científicos publicados desde el 2015 hasta el 2020, es significativo en esta muestra por conveniencia

Los doce (20) artículos científicos tomados para el análisis, fueron seleccionados a través de la una muestra por conveniencia, al no existir un estudio precedente en este tema y considerando el factor tiempo en la redacción del presente artículo. De este análisis se concluye que el $100 \%$ de los autores asocian a la marca ciudad como estrategia para el posicionamiento de la marca ciudad en urbes ecuatorianas.

El $100 \%$ de los estudios, indican que no existe un modelo estructurado claramente por los actores locales para emplear adecuadamente la sinergia de los eventos y atributos tangibles e intangibles de las ciudades. El $90 \%$ de los autores señalan que la marca ciudad se convierte en un instrumento político para posicionar a los directivos gubernamentales y no para posicionar a las ciudades.

En lo referente a la segunda etapa del análisis, los resultados más representativos son los siguientes:

Se constata que las propuestas de marca ciudad ecuatoriana no consideran como objetivo central identificar las ventajas competitivas de sus proyectos urbanos en las áreas claves sino más bien destacar las ofertas turísticas dejando en segundo plano otras importantes variables como pueden ser los factores culturales, educativos y de salud.

En esta etapa del estudio se recolectaron los datos a través de la búsqueda en redes sociales, específicamente en Facebook sobre los temas que más se mencionan sobre las ciudades analizadas para recolección de información y sus variables utilizadas para comprender su propia marca ciudad.

En la investigación, las variables seleccionadas y que sirvieron para la recolección de información a través de un modelo de Excel son las siguientes; Economía, Educación, Gobierno, Delincuencia, Religión, Salud, Seguridad, Turismo, Social, Varios, Otros.

El modelo de Excel permitió llevar a cabo una recopilación, sobre el tipo de información que se presentan periódicamente por parte de los gobiernos municipales de las ciudades investigadas desde el mes de marzo al mes de junio del 2021, a través de la red social que más se utiliza en el país que en este caso vendría a ser Facebook. 
En la figura 3, se muestra el tipo de información que inserta en su página de Facebook el gobierno municipal de la ciudad de Cuenca, en donde se puedo observar las variables más utilizadas que son Gobierno, Social y la variable Varios

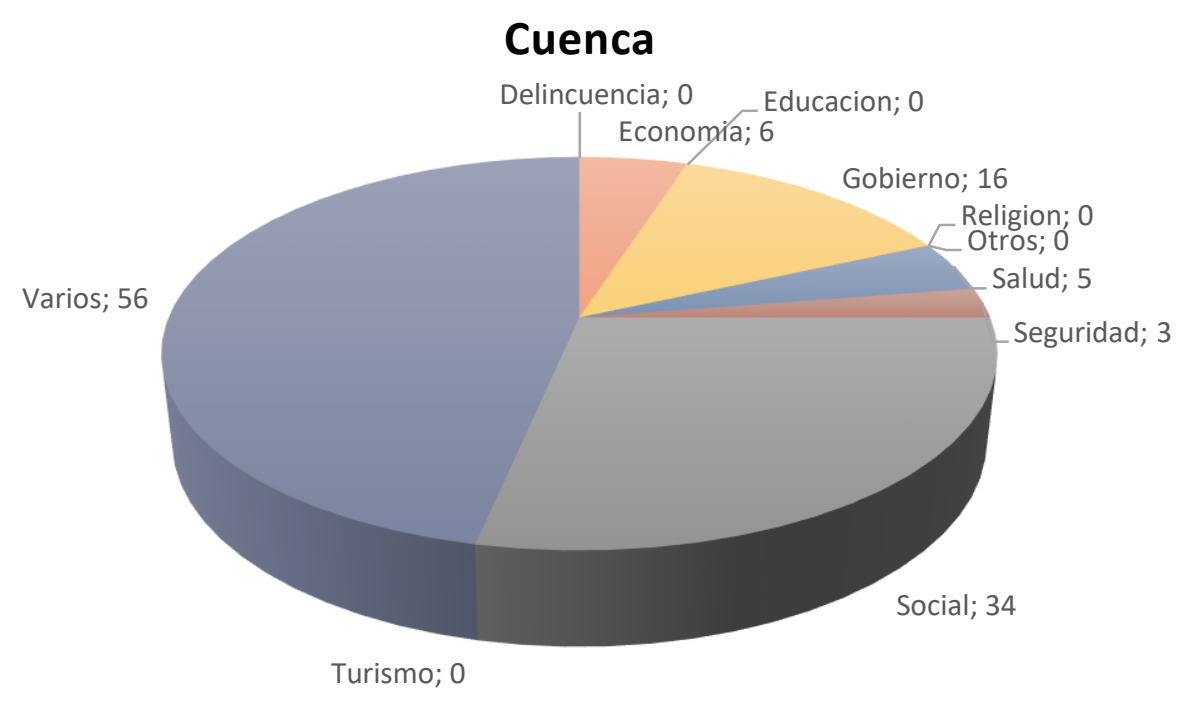

Figura 3. Información que inserta en su página de Facebook del municipio de la ciudad de Cuenca. Fuente: Elaboración propia.

De igual forma se puede apreciar en la figura 4, de cómo el gobierno municipal de la ciudad de Guayaquil se centra en las variables Gobierno, Salud, Varios y Social.

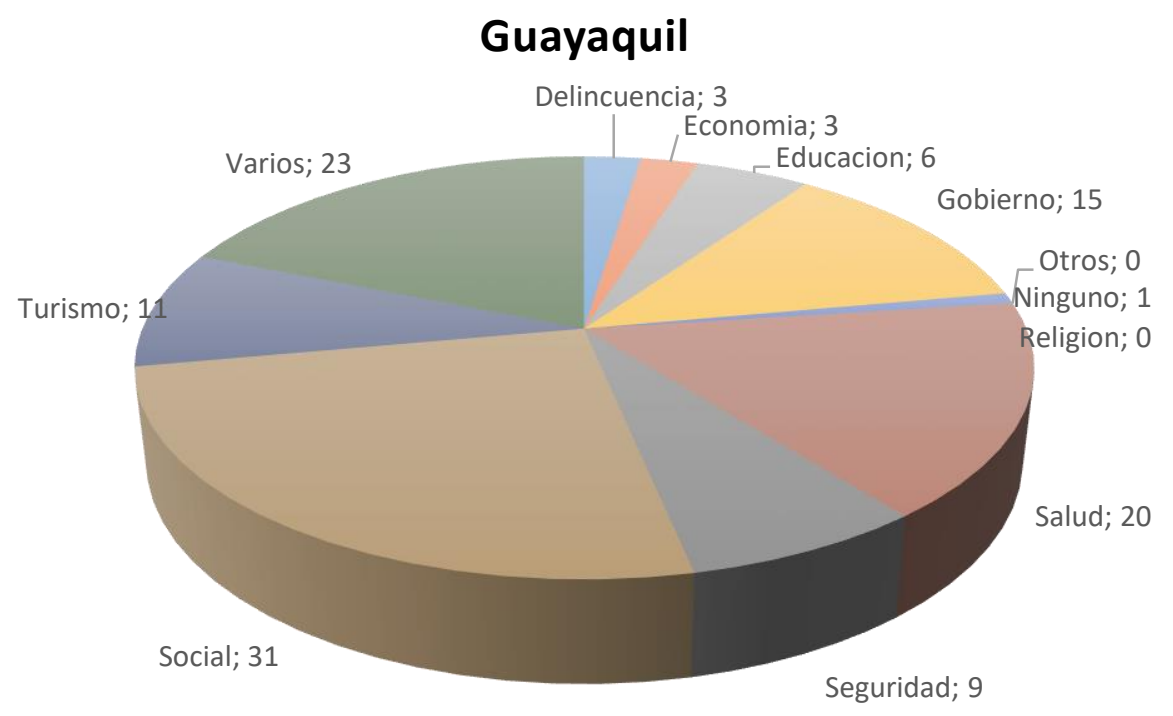

Figura 4. Información que inserta en su página de Facebook del municipio de la ciudad de Guayaquil. Fuente: Elaboración propia. 


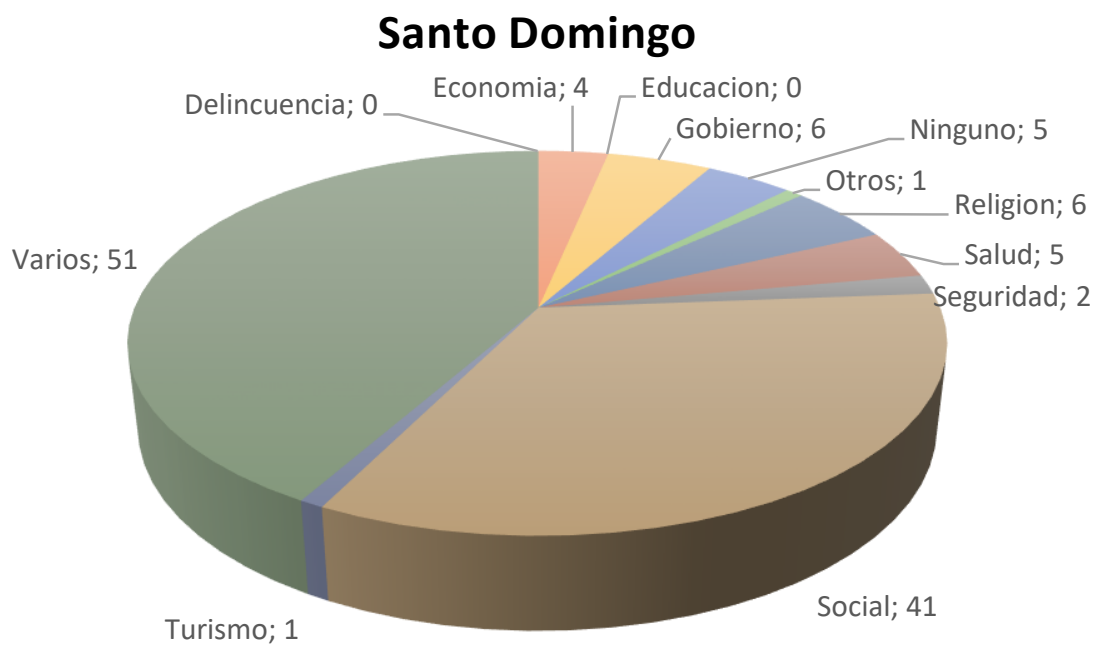

Figura 5. Información que inserta en su página de Facebook del municipio de la ciudad de Santo Domingo. Fuente: Elaboración propia.

En el caso del gobierno municipal de la ciudad Santo Domingo, como se observa en la figura 5 , de cómo las variables más utilizadas es la variable Varios y Social.

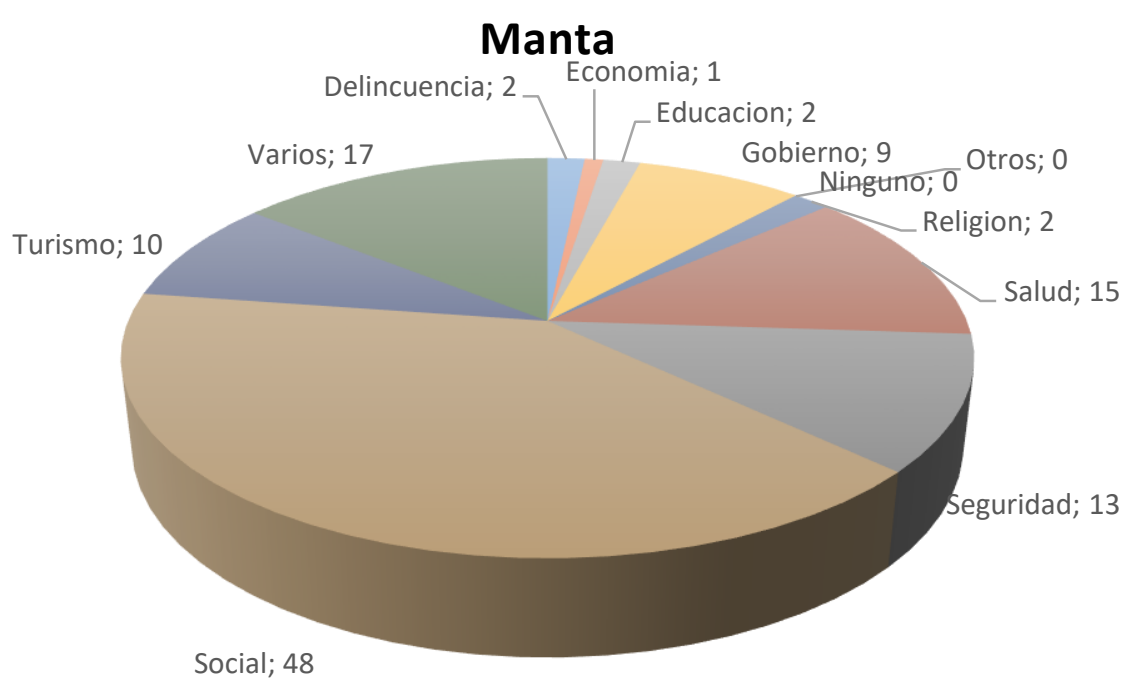

Figura 6. Información que inserta en su página de Facebook del municipio de la ciudad de Manta. Fuente: Elaboración propia.

Se puede dilucidar que en el caso del gobierno municipal de la ciudad de Manta centra sus esfuerzos en comunicar sobre variables más utilizadas es Salud, Seguridad y la variable Varios. 


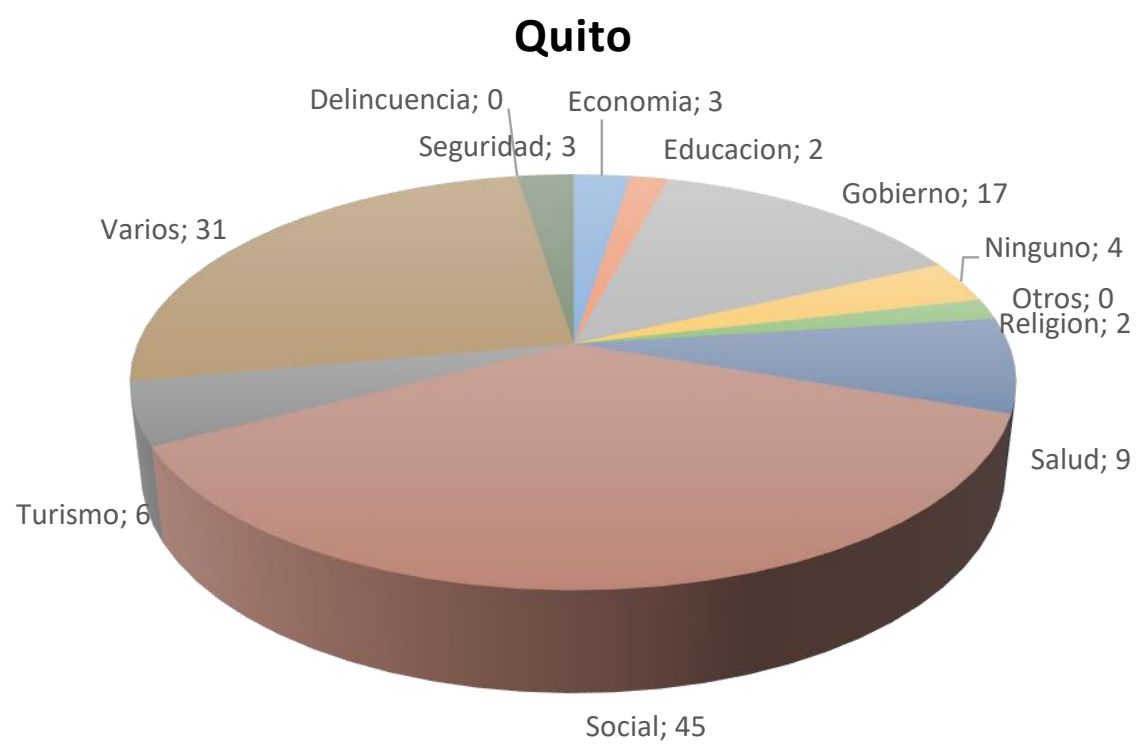

Figura 7. Información que inserta en su página de Facebook del municipio de la ciudad de Quito. Fuente: Elaboración propia.

Finalmente, en el caso del gobierno municipal de la ciudad de Quito, se observa que las variables más utilizadas es Gobierno, Varios y Social.

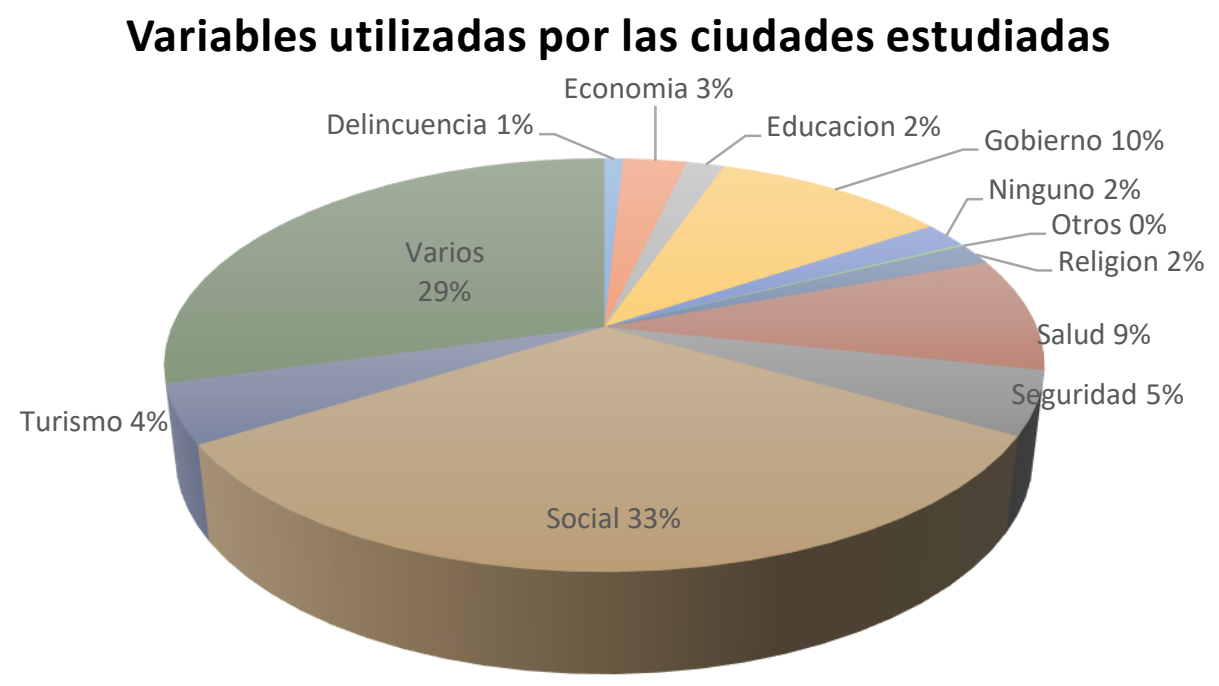

Figura 8. Las variables más utilizadas por las ciudades. Fuente: Elaboración propia.

En la figura 8, nos muestra el tipo de información que suben a la página de Facebook los gobiernos municipales de las ciudades de Cuenca, Guayaquil, Quito, Santo Domingo de los Colorados y Manta donde se observa que la variables más utilizadas por las ciudades son la Variable Social (33\%), Varios (que hace referencia al conjunto de dos o más temas que aparecieron en recolección de información en una determinada fecha) (29\%), Gobierno (10\%) y la Variable Salud (9\%), mientras que las demás variables tienen un porcentaje bajo como el de Seguridad (5\%), turismo (4\%), Economía (3\%), Educación (2\%), Religión (2\%), 
y la variable Ninguno (que hace referencia a los días en el que no subieron ningún tipo de información en la red social Facebook) (2\%).

\section{Tercera etapa}

En la tercera etapa se investigó el interés de las ciudades ecuatorianas en términos de marca ciudad, analizando los periodos 2018-2020 donde se encontró que dentro de las cinco ciudades analizadas Quito, Cuenca, Guayaquil, Santo Domingo de los Tsáchilas y Manta, el mayor porcentaje de actividades donde se incluyen temas de ciudad y en particular de Turismo recae en Quito que es la capital del Ecuador con un $78 \%$, seguido de la ciudad de Santo Domingo con un $8 \%$ de Eventos, congresos y conferencias.

A demás se demuestra que el $78 \%$ de los eventos se han realizado en el año 2020 en este periodo las ciudades se han interesado mucho más por temas de ciudad enfocándose en el turismo.

Por otra parte, estudiando estas cinco ciudades se determinó que en cuatro de ellas existe muy baja actividad en los temas mencionados anteriormente provocando así poco interés en mostrar el potencial de una ciudad llegando a no ser percibida ni regional ni internacionalmente.

La mayor parte de los resultados encontrados se hallaron en Sitios web de cada institución al mando del evento, congreso u conferencia dictada siendo así tales como Ministerios, sitios web de alcaldías o municipios, instituciones de educación superior u organizaciones privadas.

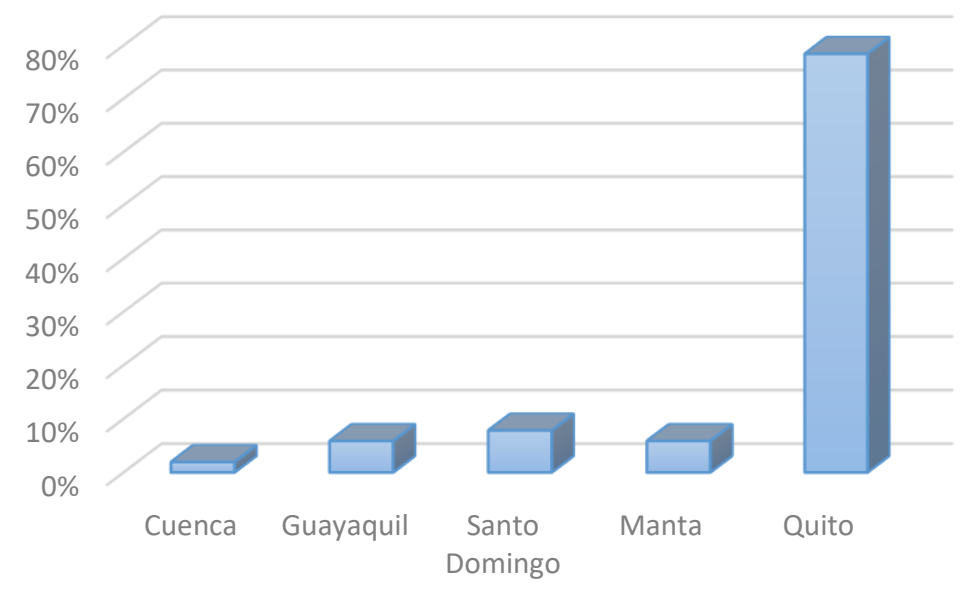

Como se aprecia en el gráfico el mayor porcentaje de realización de eventos recae en la ciudad de Quito, reflejándose pionera en las actividades para impulsar el Turismo en el Ecuador.

Figura 9. Eventos, congresos, conferencias por principales ciudades ecuatorianas. Fuente: Elaboración propia. 


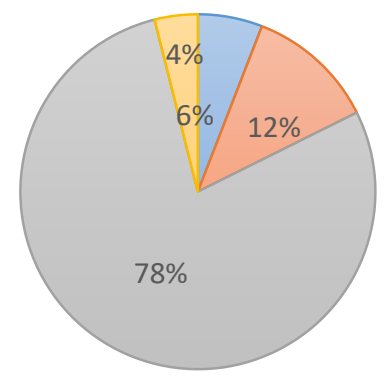

El año 2020, fue el periodo de tiempo en el que más se realizaron todo tipo de eventos virtuales por temas de pandemia.

Figura 10. Eventos, congresos, conferencias realizadas por años en los que se ejecutaron. Fuente: Elaboración Propia.

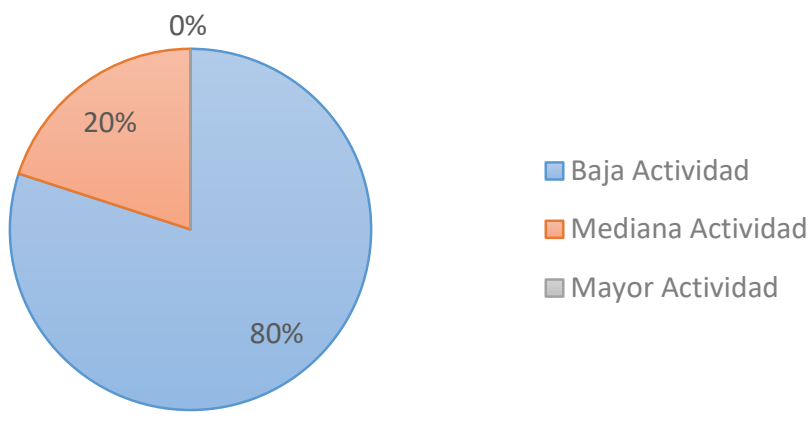

Las ciudades del Ecuador presentan gravemente un bajo nivel de actividades para impulsar al sector turístico y más aún a crear y analizar una marca ciudad bien definida.

Figura 11. Nivel de actividad de las ciudades según sus eventos realizados. Fuente: Elaboración Propia.

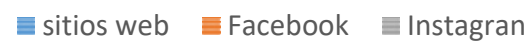

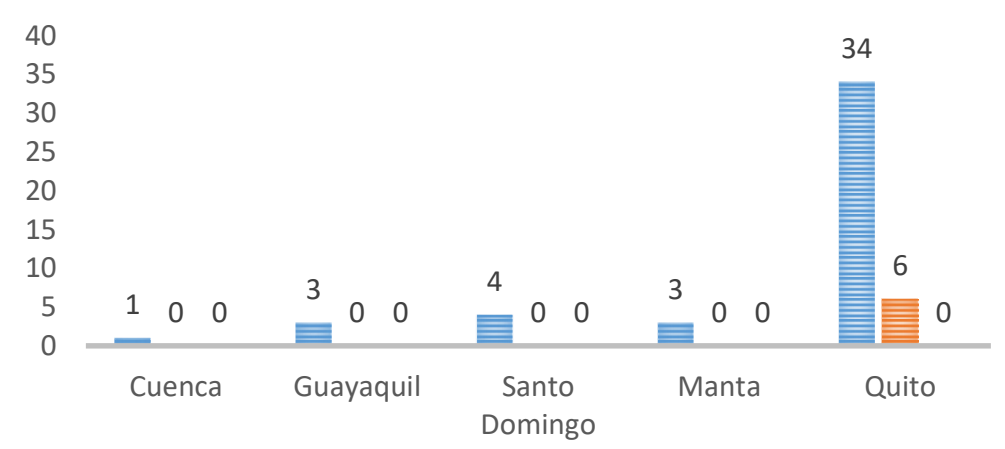

Las fuentes digitales que se utilizan a gran escala son las del propio sitio web de cada organismo que interviene en la presentación del turismo como sector urgente de reactivación.

Figura 12. Fuentes digitales. Fuente: Elaboración Propia.

\section{Tendencias en Google Trends del uso de marca ciudad}

Basándonos en las cinco ciudades mencionadas anteriormente, comenzando por la provincia Pichincha donde ha habido la máxima tendencia de búsqueda en el periodo diciembre - enero 2021 llegando a alcanzar el 12 de 100 en la escala de popularidad. Pero además se muestra que existe gran inactividad de búsqueda con respecto a estos últimos 12 meses. 


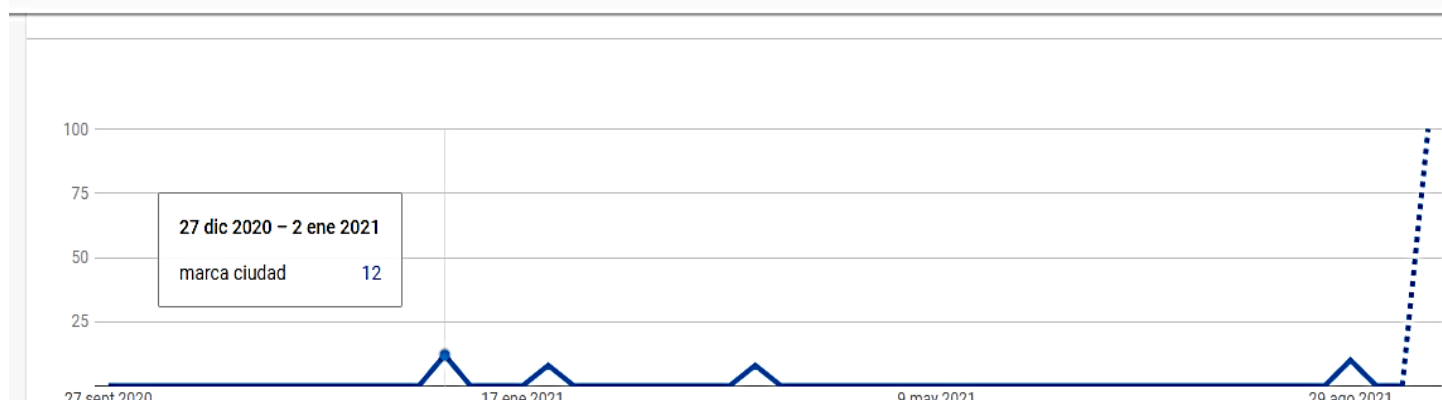

Figura 13. Búsqueda de Marca Ciudad en la Ciudad de Quito. Fuente: tomado del sitio Google trends.

Todo lo contrario, con el término "turismo" que, aunque estas dos expresiones tendrían obligatoriamente que estar entrelazadas, ya que con el desarrollo de las ciudades es sumamente necesario incrementar de manera continua las oportunidades que pueden hacer llegar a ese objetivo. El turismo sin duda alguna es una de las opciones considerada de significativo potencial en el sector y anexar métodos que incluyan temas de marca ciudad donde se permita ver los atributos de una ciudad en forma eficaz y demostrar sus ventajas comparativas, es completamente imprescindible para que dicha alternativa funcione con efectividad. En el siguiente gráfico se visualiza la franja azul que representa el termino marca ciudad y la franja roja el termino Turismo.

Donde se observa que no se encuentra ninguna semejanza de búsqueda por parte de la población y su pico de tendencia con relación al turismo en los últimos 12 meses es en el mes de febrero 2021 con 100 en la escala de popularidad.

\section{DISCUSIÓN}

A partir de los resultados del presente estudio se hace evidente de que la estrategia global de las decisoras de urbes ecuatorianas seleccionadas para el estudio sobre la utilización de la marca ciudad, no obedece a estudios multidisciplinarios, sino a valoraciones empíricas muchas veces, centradas en el cumplimiento de dos objetivos principales: personalizar la política del gobernante de turno y desarrollar estrategias de turismo.

Queda evidenciando la interpretación distorsionada que en la mayoría de los estudios consultados s se detecta sobre el concepto de marca ciudad y marketing urbano, así como entre los conceptos de imagen e identidad.

Solo tres estudios analizados hacen referencia a la necesidad de un sistema de indicadores urbanos que permitan construir la marca ciudad de forma adecuada. 
Las referencias a eventos nacionales y/o internacionales que estudien la problemática de marca ciudad de urbes ecuatorianas son escasas y generalmente se centran en el desarrollo de turismo como factor esencial de la marca ciudad.

\section{CONCLUSIONES}

Se considera inapropiado de que las propuestas en todos los casos sobre ciudades ecuatoriana es que se aplican similares planes de marketing que perseguir los mismos objetivos en distintas ciudades. Aunque existe un acuerdo generalizado de que uno de los mayores activos que posee una ciudad es su identidad, así como su carácter local que la diferencia y la hace única, en la realidad se centran en la imagen deseada y no en la real, y mucho menos se considera los elementos del ADN que deben integrar a la marca ciudad.

Los resultados dan a entender que temas importantes como economía, educación, y seguridad entre otros, no reciben el debido interés al momento de dar a conocer la marca ciudad de un lugar, si no que los gobiernos municipales del Ecuador utilizan los medios de comunicación y redes sociales (en este caso Facebook) para dar a conocer temas sociales y de gobierno con el fin de llegar a la gente y ganar más popularidad como grupo político, sin considerar desde un punto de vista holístico la identidad de la ciudad

\section{REFERENCIAS BIBLIOGRÁFICAS}

Aimacaña Toapanta, C. (2019) Desarrollo de la marca ciudad Salcedo, como función estratégica para promocionar el potencial turístico. "Trabajo de titulación en la modalidad de proyecto de investigación previo a la obtención del Título de Ingeniero en Marketing y Gestión de Negocios Facultad de Ciencias Administrativas Universidad Técnica de Ambato Ecuador

Alvarado Moreno, E.R. (2015) City branding: marca ciudad de loja. Con enfoque del marketing semiótico y antropología del consumo. Trabajo de Titulación que se presenta como requisito previo a optar el grado de Magíster en Marketing FACULTAD DE POSGRADO UNIVERSIDAD ESPÍRITU SANTO Ecuador Disponible en http://repositorio.uees.edu.ec/bitstream/123456789/2384/1/AlvaradoEricka_PAPER\% 20CITYBRANDING\%20LOJA.pdf

Anholt, S. (2008). Place branding: Is it marketing, ¿or isn't it? Place Branding and Public Diplomacy, 4(1), 1-6. https://doi.org/10.1057/palgrave.pb.6000088

Braun, E. (2012) Putting city branding into practice. J Brand Manag 19, 257-267 (2012). https://doi.org/10.1057/bm.2011.55 
Calderón Garrido, Z., \& Toapanta Espín, D. (2020). Te Quiero Cayambe: campaña marca $\begin{array}{llll}\text { ciudad. Turismo } & \text { Y } & \text { Patrimonio, } & \text { (15), }\end{array}$ https://doi.org/10.24265/turpatrim.2020.n15.09

Castro Analuiza, J. C. y Sánchez Villalba, D. M. (2020). Marca ciudad: naturaleza y alcance desde el hexágono de Anholt. Revista Científica Ecociencia, 7(3), 1-29. https://doi.org/10.21855/ecociencia.73.322

Corral, C. S. y Pineda, J. B. (2017) Branding corporativo como estrategia para el reconocimiento de la marca Ciudad Atuntaqui D Trabajo Previo A La Obtención Del Título De Ingeniera En Desarrollo Social Y Cultural Desarrollo Social y Cultural Universidad De Otavalo http://repositorio.uotavalo.edu.ec/bitstream/52000/97/1/UOPG-DES-2017-02.pdf

Crudele, N. (2018): "Estudio de la marca Ciudad Loja como atractivo de turismo nacional y extranjero en el Ecuador", Revista Turydes: Turismo y Desarrollo, n. 25 (diciembre / dezembro 2018). En línea: https://www.eumed.net/rev/turydes/25/loja.html http://hdl.handle.net/20.500.11763/turydes25loja

Elizagarate Gutiérrez, V. (2008): Marketing de ciudades. Estrategias para el desarrollo de ciudades atractivas y competitivas en un mundo global. Madrid, Ediciones Pirámide

Freire, J. R. (2009), Local people: A critical dimension for place brands", Journal of Brand Management, Vol. 16 No. 7, pp. 420-438. Recuperado el 20 de febrero 2021 https://www.researchgate.net/publication/233638499_Local_People'_a_critical_dime nsion_for_place_brands

Galiano Bustamante, A. C. (2015). Guía para el desarrollo de city branding mediante el uso de storydoing y ambient marketing para ciudades consideradas Patrimonio cultural Nacional en Ecuador. Caso: San Miguel de Ibarra. Tesis de pregrado Universidad de las Américas, Quito. UDLA-EC-TPU-2015-Recuperado el 23 de marzo 2021 20http://dspace.udla.edu.ec/handle/33000/6826

Gertner, D (2021) Unfolding and configuring two decades of research and publications on place marketing and place branding. Place Brand Public Dipl 7, 91-106 (2011). https://doi.org/10.1057/pb.2011.7

Giraldo Cardona, C.M. y Martínez María-Dolores, S.M. (2017) Análisis de la actividad y presencia en facebook y otras redes sociales de los portales turísticos de las comunidades autónomas españolas Cuadernos de Turismo, № 39, (2017); pp. 239- 
264 Universidad de Murcia ISSN: 1139-7861 EISSN: 1989-4635 DOI: http://dx.doi.org/10.6018/turismo.39.290521

Godoy Zúñiga, M.E. y Godoy Delgado, D. (2017) Diseño de una propuesta de marca territorial para la ciudad de Loja como estrategia turística", Revista Turydes: Turismo y Desarrollo, n. 22 (junio 2017). Recuperado e; 224 de mayo 2021 http://www.eumed.net/rev/turydes/22/turismo-loja-ecuador.html

González Cabrera, C.R., Padilla Cardoso, A.C., Piedra Corral, M.E. (2017) Marca ciudad cuenca y la percepción de su imagen en los ciudadanos Tesis de Pregrado Licenciatura en Comunicación Social y Publicidad Facultad de Filosofía, Letras y Ciencias de la Educación Universidad del Azuay Disponible en http://dspace.uazuay.edu.ec/handle/datos/4046 Consultado 30 de marzo 2021

Hanna, S. and J. Rowley, 2015, "Towards a model of the place brand web". Tourism Management, 48: 100-112.Recuperado el 23 de mayo 2021 en https://www.researchgate.net/publication/272407266_Towards_a_model_of_the_Pla ce_Brand_Web

Jacobsen, B. P., 2009, "Investor-based place brand equity: A theoretical framework". Journal of Place Management and Development, 2: 70-84. Recuperado 7 de Julio 2021 https://www.scopus.com/record/display.uri?eid=2-s2.084992963158\&origin=inward\&txGid=efba09f1b98c0e4d4bbb653ddf06165f

Jacobsen, B.P. (2009) Investor-based place brand equity: A theoretical framework. Journal of Place Management and Development 2 (1): 70-84. Recuperado el 2 de junio 2021 http://citeseerx.ist.psu.edu/viewdoc/download?doi=10.1.1.630.9095\&rep=rep1\&type= pdf

Kotler, P.; Asplund, C.; Rein, I. y Haider, D. (1999). Marketing places Europe: Attracting investments, industries, residents and visitors to European cities, communities, regions and nations. Londres: Pearson Education.

Magnoni, F., Valette-Florence, PP., De Barnier, V. (2021) Modeling the effects of place heritage and place experience on residents' behavioral intentions toward a city: A mediation analysis, Journal of Business Research, Volume 134, Pages 428-442, ISSN 0148-2963, https://doi.org/10.1016/j.jbusres.2021.04.069.

Noisette, P. y Vallerugo, F. (1996). Marketing des villes. París: ESSIC 423 PP ISBN-10: 2708119613 ISBN-13: 978-2708119611 Francia 
Palmer, A.; Koenig-Lewis, N., Elinor Medi Jones, L. (2013) The effects of residents' social identity and involvement on their advocacy of incoming tourism Tourism Management 38:142-151 DOI:10.1016/j.tourman.2013.02.019

Pancorbo de Sandoval, J.A. (1999). Desarrollo de indicadores urbanos en la gestión de marketing de ciudad; Tesis Doctoral Universidad de León España

Paredes Zevallos, Y. (2020). Estudio de percepción, pertinencia y presencia de la Marca Ciudad Quito como destino turístico. Trabajo de Titulación previo a la obtención del Título de Licenciada en Turismo Histórico Cultural. Carrera de Turismo Histórico Cultural. Quito: UCE. 183 p. Ecuador

Park, S. y Petrick, J. (2006) J Destinations' Perspectives of Branding anuary 2006Annals of Tourism Research 33(1):262-265 DOI: 10.1016/j.annals.2005.10.007

Ponce-Andrade, J. E., Palacios-Molina, D. L., Solis-Cedeño, V. J., Villafuerte-Muñoz, W. O., Villamarin-Villota, W. H., \& Álvarez-Cárdenas, C. A. (2020). El marketing digital y su impacto en el posicionamiento de la marca ciudad: Manta - Ecuador. Revista Científica FIPCAEC (Fomento De La investigación Y publicación En Ciencias Administrativas, Económicas Y Contables). ISSN: 2588-090X. Polo De Capacitación, Investigación Y Publicación (POCAIP), 5(5), 27-59. https://doi.org/10.23857/fipcaec.v5i5.184

Poveda Benites, S.G. y Gómez Behr, P.A. (2020) Valores ciudadanos en la construcción de la marca país. Un análisis ecuatoriano Podium no.36 Samborondón dic./may. 2019 http://scielo.senescyt.gob.ec/scielo.php?script=sci_arttext\&pid=S2588096920190001 00073

Romero Baque, A., \& Narváez Jadán, J. (2016). Estratégias de city branding para reposicionar la imagen de la comuna Montañita perteneciente a la provincia de Santa Elena, año 2017 Tesis. Facultad de Ciencias Administrativas Ingeniería en Marketing y Negociación Comercial Tesis - Ingeniería en Marketing y Negociación Comercial Recuperado a partir de http://repositorio.ug.edu.ec/handle/redug/47375

Tobar, J., y Moreno, K. (2020). Estrategia Marca Ciudad y su Importancia dentro del Turismo de la Ciudad de Latacunga. Revista Electrónica de Ciencia y Tecnología del Instituto Universitario de Tecnología, 6(2) recuperado 8 de junio 2021 https://redib.org/Record/oai_articulo2771152-estrategia-marca-ciudad-y-suimportancia-dentro-del-turismo-de-la-ciudad-de-latacunga 
Zambrano Mendoza, L.A. (2015) Estudio sobre la creación de la marca ciudad Chone como elemento significativo comunicacional de fortalecimiento de identidad y memoria colectiva para los ciudadanos de la zona urbana del cantón. Escuela de Ciencias Administrativas. UIDE. Quito. 107p.Ecuador

Zenker, S.; Braun, E.; Petersen,S. (2017) Branding the destination versus the place: The effects of brand complexity and identification for residents and visitors, Tourism Management, Volume 58, 2017, Pages 15-27, ISSN 0261-5177, Recuperado el 23 de Agosto 2021 https://www.sciencedirect.com/science/article/pii/S0261517716301868 